\title{
Water resources and environment in Australia
}

\author{
Bellie Sivakumar
}

(C) Springer-Verlag Berlin Heidelberg 2013

Australia is the driest inhabited continent in the world: the mean annual rainfall is only about $465 \mathrm{~mm}$. The country has also one of the most variable climates in the world: tropical in the north to arid in the middle to temperate in the south, and still others (e.g. continental, oceanic). As a consequence, there is significant variability in hydrology and water resources (e.g. rainfall, streamflow) in both space and time: for instance, more than $80 \%$ of the country gets an annual rainfall of $<600 \mathrm{~mm}$, but the tropical far north receives over 4,000 $\mathrm{mm}$; and rainfall is generally more in winter than in summer, but it is the opposite in the far north. The extreme spatial and temporal variability in rainfall also contributes to frequent floods and droughts in different parts of the country: the 2010-2011 floods in the northeast state of Queensland (QLD) and the 2001-2009 drought (the Millennium Drought) in the southeast states of New South Wales (NSW), Victoria (VIC), and Tasmania (TAS) and also the Australian Capital Territory (ACT) are just two of the many recent examples.

Australia is an island continent, far away from much of the rest of the world. It is also home to some unique ecosystems and species. The Great Barrier Reef is the world's largest coral reef system, composed of over 2,900 individual reef systems and 900 islands stretching for over 2,600 km over an area of $\sim 344,000 \mathrm{~km}^{2}$, located in the Coral Sea off the coast of QLD. Among the unique animal, bird, and plant

B. Sivakumar $(\square)$

School of Civil and Environmental Engineering, The University of New South Wales, Sydney, NSW 2052, Australia

e-mail: s.bellie@unsw.edu.au

B. Sivakumar

Department of Land, Air and Water Resources, University of California, Davis, CA 95616, USA

e-mail: sbellie@ucdavis.edu species are the kangaroo, the koala, the platypus, and the emu. Australia's distance from the rest of the world and its unique ecosystems put additional stress on the nation on various fronts. For instance, it becomes extra imperative to be self-sufficient in food production, rather than depending on imports from far off countries, to meet the nation's needs. Elimination of the potential spread of diseases from other countries, including through imports of food products, plants, and animals, is an absolute priority. These have contributed to, among others, significant exploitation of water resources and environment in the Murray-Darling Basin (MDB) over the past several decades.

All these observations clearly indicate that proper planning and management of Australia's water resources and environment is already at a critical stage. Looking at the projections of future population (if the current trend continues, the country's population is expected to reach 36 million by around 2050; see Australian Bureau of Statistics 2008) and anticipated impacts of climate change (increased temperature, reduced rainfall, increased frequency and intensity of floods and droughts; see CSIRO and Bureau of Meteorology 2007; Cleugh et al. 2011), this problem will become even far more vital and challenging. The relevant issues and questions to address are very many, including: (1) How can modeling and prediction of hydrologic processes be done better? (2) What are the impacts of climate change on water and environment? (3) Can the various water demands, including environmental flow requirements, be met adequately? (4) How does catchment landscape evolve? (5) In what ways a better understanding of floods and minimization of their risks be achieved? (6) What are the uncertainties in water allocation, and how to deal with them? (7) What is the role of information modeling in water resources? and (8) What are the challenges in managing waters shared across political boundaries? 
The current Special Issue compiles some important research activities that address the above issues, and others, associated with the water resources and environment in Australia. The issue consists of 11 papers, contributed by a total of 35 authors, from several universities/institutions/ government organizations (and others) across Australia and elsewhere. The papers together cover a wide range of topics, study water and environmental issues in different regions/states (including the Murray-Darling Basin), analyze a variety of water and environmental data, develop and/or test different scientific concepts, employ a host of mathematical methods and measurement techniques, and offer important directions for the future. It is my hope that this compilation will form an important contribution to research on Australian water resources and environment.

Acknowledgments First of all, my sincere thanks to George Christakos, the Editor-in-Chief of SERRA, for his encouragement and support for this Special Issue in the first place. I very much appreciate the time and effort by George as well as by Ellen Klink and Helen James, at the SERRA Editorial Office, throughout the review process.
The authors of the contributions deserve my special thanks for their support and participation in this endeavor, despite their numerous commitments and time constraints. The Special Issue has also benefited from the following reviewers (in alphabetical order): Claudia Baldwin, Ni-Bin Chang, Barry Croke, Martin Evans, Suzanne Grenfell, Yang Hong, Young-Hoon Jin, Fiona Johnson, Vinayakam Jothiprakash, Yi Liu, Kaveh Madani, Irene Marzolff, Goloka Sahoo, Joy Sanyal, Fran Sheldon, Jeng-Tzong Shiau, Jian-Ping Suen, Jeremy Tandy, and Laura Uusitalo. Their timely and constructive reviews have certainly enhanced the quality of the contributions, and my sincere thanks to each and every one of them.

\section{References}

Australian Bureau of Statistics (2008) Population projections: Australia. Australian Bureau of Statistics, Canberra

Cleugh H, Smith MS, Battaglia M, Graham P (eds) (2011) Climate change: science and solutions for Australia. CSIRO Publishing, Victoria

CSIRO and Bureau of Meteorology (2007) Climate change in Australia. Technical Report. www.climatechangeinaustralia. gov.au. Accessed 14 Aug 2013 